\title{
Pertimbangan Etika Klinik dan Medikolegal untuk Pengelolaan Anestesi pada Kasus Cedera Otak Traumatik
}

\author{
Taufik Suryadi*), Kulsum**) \\ ${ }^{*}$ Bagian Ilmu Kedokteran Forensik dan Medikolegal, ${ }^{* *}$ Bagian Anestesiologi dan Terapi Intensif Fakultas \\ Kedokteran Universitas Syiah Kuala/Rumah Sakit Umum Daerah dr.Zainoel Abidin Banda Aceh
}

\begin{abstract}
Abstrak
Cedera Otak Traumatik (COT) merupakan penyebab utama kematian dan kesakitan pada anak-anak dan dewasa muda di seluruh dunia. Dilaporkan sebuah kasus COT pada seorang pasien anak laki-laki berusia 5 tahun yang jatuh dari lantai 2. Pasien didiagnosis dengan cedera kepala berat dengan perdarahan epidural dan subdural dengan level ASA 3-4. Dilema etis yang dihadapi ahli anestesi adalah tindakan anestesi berisiko tinggi tetapi kemungkinan penyelamatan nyawa tidak berhasil, sehingga apakah masih tetap dilakukan operasi atau hanya diberikan terapi suportif?. Laporan ini membahas tentang pemecahan dilema etik dan medikolegal berdasarkan teori etika klinik. Hasil pertimbangan etika dan medikolegal pada kasus ini dilakukan secara komprehensif dengan menghasilkan keputusan bersama antara tim dokter dengan keluarga pasien. Dengan pemberian informasi yang adekuat mengenai indikasi medik dengan tetap memperhatikan sudut pandang permintaan (keinginan) pasien, kualitas hidup maupun fitur kontekstual maka meskipun pada akhirnya pasien ini tidak berhasil diselamatkan, paling tidak keluarga pasien puas atas pelayanan yang telah diberikan.
\end{abstract}

Kata kunci: anestesia, cedera otak traumatik, etika klinik, medikolegal

JNI 2020, 9 (2): 108-116

\section{Clinical Ethics and Medicolegal Considerations for Anesthesia Management in Cases of Traumatic Brain Injury}

\begin{abstract}
Traumatic Brain Injury (COT) is a leading cause of death and illness in children and young adults throughout the world. A case of COT was reported in a 5-year-old boy who fell from the 2 nd floor. The patient was diagnosed with a severe head injury with epidural and subdural bleeding with ASA levels 3-4. The ethical dilemma faced by the anesthesiologist is the high-risk anesthetic procedure but the possibility of life saving is unsuccessful, so whether the surgery is still being performed or only given supportive therapy?. This report discusses solving ethics and medicolegal dilemmas based on clinical ethics theory. The results of ethical and medicolegal considerations in this case were carried out comprehensively by producing a joint decision between the team of doctors and the patient's family. By providing adequate information regarding medical indications while still giving attention to the patients' preferences, quality of life and contextual features, even though these patients were ultimately unsuccessful, at least the patient's family was satisfied with the services provided.
\end{abstract}

Key words: anesthesia, clinical ethics, medicolegal, traumatic brain injury

JNI 2020, 9 (2): 108-116

This article is licensed under a

Creative Commons Attribution-NonCommercial-ShareAlike 4.0 International License.

CTaufik Suryadi, Kulsum (2020) under the CC-BY-NC-SA license 


\section{Pendahuluan}

Trauma kepala merupakan bentuk trauma yang dapat merusak struktur dan fungsi dari bagianbagian kepala seperti kulit kepala, tulang tengkorak, dan otak. ${ }^{1}$ Istilah trauma kepala lebih tepat didefinisikan dalam cedera otak traumatik (COT). COT merupakan trauma kepala yang menyebabkan gangguan fungsi otak dengan gejala klinis seperti kebingungan, penurunan kesadaran, kejang, koma, dan gangguan motorik dan sensorik serta terjadi defisit neurologis. ${ }^{2}$ Pada tahun 2017, kasus cedera kepala yang datang ke Rumah Sakit Umum Daerah dr. Zainoel Abidin Banda Aceh sebanyak 167 pasien dengan usia berkisar 3136 tahun. $^{3}$ Trauma kepala merupakan penyebab utama kematian di Amerika Utara pada usia 1 sampai 45 tahun. Insidensi trauma kepala di USA didapatkan 538,2 kasus dalam 100.000 populasi, di Eropa sebanyak 235 dalam 100000 populasi dan Australia 322 dalam 100.000 populasi. ${ }^{3,4}$ Berdasarkan penelitian yang dilakukan pada 29 negara menunjukkan angka kematian akibat trauma kepala di Eropa yaitu 303/100,000/tahun, Afrika 316.42/100,000/tahun dan Asia sebanyak 56.3/100,000/tahun. ${ }^{5}$ Sedangkan untuk proporsi rata-rata kejadian trauma kepala di Indonesia adalah $0,4 \%{ }^{6}$

Pada trauma kepala ringan, gejala yang sering timbul adalah perubahan perilaku dan perubahan neuropsikologis. Adanya pendarahan yang terjadi pada pasien dengan trauma kepala menjadi petunjuk bagi tenaga medis untuk mengetahui lokasi trauma kepala. Perdarahan akibat trauma intrakranial biasanya terjadi di ruang epidural, ruang subdural, ruang subarachnoid, jaringan otak (perdarahan intra serebral) dan ventrikel serebral. ${ }^{2}$ Pada saat ini, pasien yang tetap survive dengan COT serius, walau bagaimanapun menimbulkan sejumlah pertimbangan etis. Kebanyakan pasien COT adalah orang dewasa muda yang sebelumnya tampak bugar dan sehat namun karena COT mereka merasakan kondisi tubuh yang tidak dapat diterima selama bertahuntahun. Selain itu, tingkat ketergantungan mereka kepada keluarga menjadi beban yang cukup besar. ${ }^{7}$ Dalam upaya untuk mengatasi masalah etik ini, dalam dunia kedokteran khususnya di setting klinis sering digunakan pendekatan etika klinik yang diperkenalkan oleh Jonsen dan Siegler yang dengan pertimbangan medis yang sistematis sesuai dengan indikasi medik, preferensi pasien, kualitas hidup dan fitur kontekstual. ${ }^{8}$ Banyak tantangan etis yang mungkin timbul selama penilaian neuropsikologis. Makalah ini menyoroti pertimbangan etis yang terkait dengan penilaian neuropsikologis individu dengan diagnosa COT. Masalah mengenai kompetensi profesional, memberikan dan memperoleh persetujuan, pemilihan dan administrasi tes neuropsikologis, mengkomunikasikan hasil penilaian secara efektif, dan bekerja sebagai bagian dari tim multidisiplin dibahas dengan rekomendasi praktis. Pada akhirnya, pemahaman yang komprehensif tentang masalah ini serta integrasi sumber daya untuk memandu praktik klinis akan berkontribusi pada pengambilan keputusan etis dan praktik profesional yang baik. ${ }^{9}$ Ketika seseorang menderita COT, ada konsekuensi yang luar biasa yang tidak hanya untuk pasien, tetapi juga untuk keluarga, penyedia layanan kesehatan, dan banyak lainnya yang memiliki hubungan dengan pasien. Keputusasaan dan kesia-siaan adalah emosi yang umum dirasakan oleh pasien dengan COT. Dalam kerangka ini, sangat banyak timbul dilemma etis dan moral. ${ }^{8}$

\section{Kasus}

\section{Anamnesis}

Seorang anak laki laki berusia 5 tahun dengan berat badan $10 \mathrm{~kg}$, dibawa ke rumah sakit dengan keluhan cedera kepala akibat terjatuh dari lantai 2 di sebuah masjid di Banda Aceh 15 menit sebelum masuk ke rumah sakit. Pada saat masuk rumah sakit pasien mengalami penurunan kesadaran, namun ibunya menyangkal pasien kejang dan muntah. Rencana akan dilakukan kraniotomi emergensi untuk evakuasi bekuan darah akibat epidural dan subdural hematoma temporoparieto-occipital sinistra.

\section{Pemeriksaan Fisik}

Pada pemeriksaan fisik airway clear, breathing dengan respiratory rate $24 \mathrm{kali} / \mathrm{menit}$, circulation dengan nadi 104 kali/menit, Glasgow Coma 
Scale (GCS) awal masuk 9 dengan E2M5V2, pupil isokor $3 \mathrm{~mm} / 3 \mathrm{~mm}$, status lokalisata pada regio capitis terdapat hematom pada regio temporoparieto-occipital. Status neurologis: reflek cahaya langsung dan tidak langsung $+/+$, terdapat parese nervus VII dextra. Pada fungsi motorik kesan lateralisasi kanan, reflex fisiologis $(+)$, reflex patologis (-), fungsi sensorik belum dapat dinilai.

\section{Pemeriksaan Penunjang}

Pemeriksaan rontgen torak jantung dan paru dalam batas normal. Laboratorium didapatkan Hemoglobin 10,8 g/dl, Hematokrit $32 \%$, leukosit $15400 / \mathrm{mm} 3$, trombosit $459000 / \mathrm{mm} 3$, gula darah $180 \mathrm{mg} / \mathrm{dL}$, Natrium $144 \mathrm{mEq} / \mathrm{L}$, Kalium $3,7 \mathrm{mEq} / \mathrm{L}, \mathrm{Cl} 112 \mathrm{mEq} / \mathrm{L}$. Dari hasil CT scan kepala didapatkan ada EDH dan SDH pada regio temporoparieto-occipital sinistra seperti tampak pada gambar 1 .

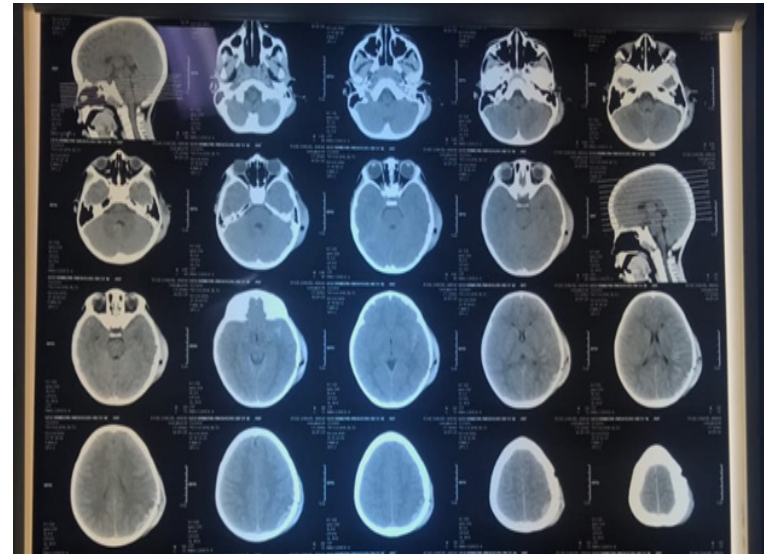

Gambar 1. EDH dan SDH pada regio temporoparieto-occipital sinistra

\section{Pengelolaan Anestesi}

Pasien dikonsultasikan ke bagian anestesi untuk dilakukan kraniotomi emergensi untuk evakuasi bekuan darah akibat epidural dan subdural hematoma pada regio temporoparieto-occipital sinistra. Pada pemeriksaan pra anestesi kondisi pasien pada level ASA III, pada pasien didapatkan airway clear, breathing dengan respiratory rate 35 kali/menit, $\mathrm{SpO}_{2} 92 \%$, circulation dengan tekanan darah $70 / 30 \mathrm{mmHg}$, nadi $140 \mathrm{kali} / \mathrm{menit}$, pupil anisokor $3 \mathrm{~mm} / 4 \mathrm{~mm}$, pasien mengalami peningkatan tekanan intrakranial akut, GCS menurun menjadi 6 (E2M2V2), nyeri kepala $(+)$, muntah $(+)$, kejang $(+)$. Pasien dimasukkan ke dalam kamar operasi dengan terpantau saat itu hemodinamik prainduksi yaitu tekanan darah $60 / 30 \mathrm{mmHg}$, frekuensi nadi 150 kali per menit, frekuensi napas 35 kali per menit dan saturasi $\mathrm{O}_{2}$ 90\%. Koinduksi menggunakan fentanyl 10 mcg. Induksi menggunakan propofol $10 \mathrm{mg}$, rocuronium $1 \mathrm{mg}$, intubasi dengan ETT no. 4 cuff. Pemeliharaan anestesi dengan fraksi oksigen $50 \%+$ air + sevofluran $1,5 \%$ dan rocuronium 5 $\mathrm{mg}$. Monitoring tanda-tanda vital selama operasi dilakukan dengan alat non-invasif meliputi EKG, $\mathrm{SpO}_{2}, \mathrm{EtCO}_{2}$, suhu, dan urin. Selama operasi, tekanan darah berkisar antara 50-80/00-50 $\mathrm{mmHg}$, denyut jantung berkisar 100-50 x/menit, saturasi oksigen 90-98\%. Pada saat operasi sistol menurun tapi masih dalam batas normal dan heart rate naik karena perdarahan yang terjadi. Kontrol ventilator dengan modus Asist Volume TV $80 \mathrm{ml}, \mathrm{FiO}_{2}$ 50\%, I: E =1:1,5, RR 25x/i, End tidal $\mathrm{CO}_{2} 30 \mathrm{mmHg}$. Jumlah urin $15 \mathrm{ml}$ dalam 2 jam, dan warna urin kuning kurang jernih. Operasi berlangsung selama 2 jam. Perdarahan selama operasi sekitar $20 \%$ atau sekitar $150 \mathrm{ml}$ dari Estimated Blood Volume $=75 \times 10 \mathrm{~kg}=750$ $\mathrm{ml}$ darah. Pemberian cairan rumatan $40 \mathrm{cc} /$ jam ditambah cairan transfusi PRC $150 \mathrm{ml}$ untuk mengganti perdarahan. Cairan untuk mengganti penguapan selama operasi 2 jam yaitu $2 \times 2 \times 10$ $=40 \mathrm{ml}$. Jadi total cairan $\mathrm{NaCl} 0,45 \%$ dextrose $5 \%$ yang diberikan yaitu $150 \mathrm{ml}$ selama 2 jam. Setelah operasi pasien dirawat di Pediatric Intensive Care Unit (PICU) dalam keadaan terintubasi dengan ventilator modus SIMV TV $80 \mathrm{ml}, \mathrm{FiO}_{2} 60 \%$, I: E = 1: 1,5, RR 25 x/i. Obat paska operasi yang diberikan adalah parasetamol $200 \mathrm{mg} / 8 \mathrm{jam}$, ceftriakson $750 \mathrm{mg} / 12 \mathrm{jam}$. Saat di PICU keaadaan tidak stabil dan dirawat selama 2 hari kemudian pasien exitus. Tanda vital selama operasi yang terjadi pada jam 11.00 adalah perdarahan ditandai dengan sistol turun dan laju jantung cenderung naik.

\section{Pertimbangan Etika Klinik}

Level risiko di bidang anestesi berdasarkan American Society of Anesthesiologist (ASA) adalah 3 dan kemungkinan kematian di meja operasi (Death on the table/DOT) dapat 


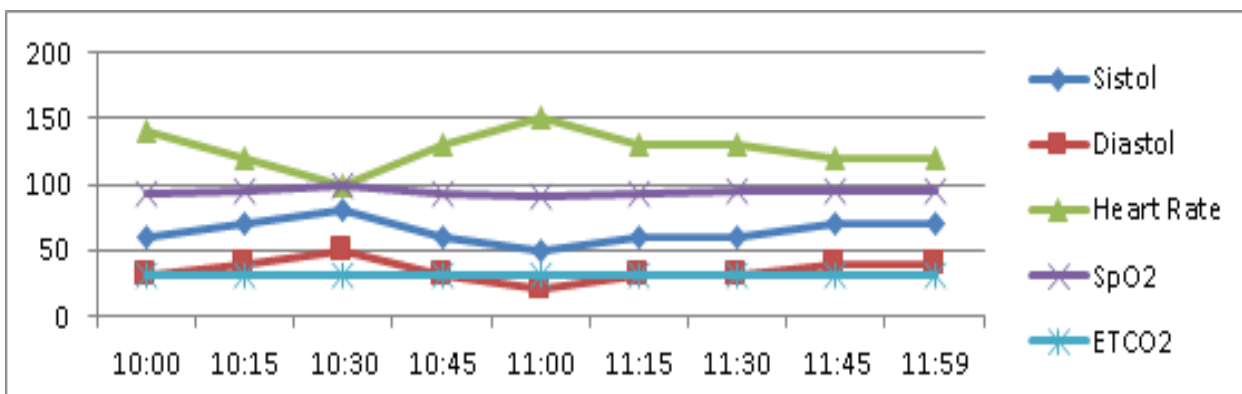

Grafik 1. Grafik Tanda Vital Selama Operasi

terjadi. Dilema etis yang dihadapi ahli anestesi adalah tindakan anestesi berisiko tinggi tetapi kemungkinan penyelamatan nyawa tidak berhasil sehingga apakah masih tetap dilakukan operasi atau hanya diberikan tindakan suportif. Dalam upaya untuk mengatasi masalah ini, digunakan pemecahan dilema etik berdasarkan teori etika klinik yang diusulkan oleh Jonsen dan Siegler dengan pertimbangan sistematis terhadap indikasi medis, preferensi pasien, kualitas hidup dan fitur kontekstual. ${ }^{8}$

\section{Pembahasan}

\section{Kondisi pasien}

Cedera kepala traumatik sering terjadi pada usia anak-anak usia 0-4 tahun, dewasa muda 15-19 tahun dan usia tua 65 tahun atau lebih. Berdasarkan jenis kelamin frekuensi terjadinya COT pada pria lebih banyak daripada wanita dengan penyebab utama adalah jatuh atau kecelakaan lalu lintas dengan kendaraan bermotor. Berdasarkan tingkat kesadaran menurut skor Glasgow Coma Scale (GCS) maka COT dapat diklasifikasikan pasca resusitasi, yaitu cedera kepala ringan (GCS 1315), cedera kepala sedang (GCS 9-12), dan cedera berat $(\mathrm{GCS}<8) .{ }^{10-12}$ Pasien ini mengalami cedera otak primer yang terjadi akibat benturan langsung pada kepalanya saat terbentur dengan lantai masjid. Cedera kepala diklasifikasikan ke dalam cedera primer dan cedera sekunder. Klasifikasi ini berguna untuk pertimbangan terapi. Cedera primer adalah kerusakan yang ditimbulkan oleh impak mekanis dan stres aselerasi-deselerasi pada tulang kepala dan jaringan otak, mengakibatkan patah tulang kepala (tulang kepala atau basis kranii) dan lesi intrakranial. ${ }^{11,12}$ Lesi intrakranial dapat diklasifikasikan ke dalam dua tipe yaitu lesi difus dan fokal. Lesi difus dapat dibagi lagi menjadi brain concussion (bila hilangnya kesadaran berakhir $<6$ jam) dan diffus axonal injury/DAI (bila hilangnya kesadaran berakhir $>$ $6 \mathrm{jam})$. Sementara lesi fokal juga beberapa macam diantaranya memar otak, epidural hematom $(\mathrm{EDH})$, subdural hematom (SDH), intraserebral hematom (IH). Cedera sekunder berkembang dalam menit, jam, atau hari sejak cedera pertama dan menimbulkan kerusakan lanjutan dari jaringan saraf. Penyebab paling umum dari cedera sekunder adalah hipoksia dan iskemi serebral. Cedera sekunder dapat disebabkan halhal berikut: 1) disfungsi respirasi (hipoksemia, hiperkarbia), 2) instabilitas kardiovaskuler (hipotensi, curah jantung rendah), 3) peningkatan tekanan intrakranial, dan 4) gangguan parameter biokimiawi lainnya. ${ }^{10-13}$

Pada pasien ini dijumpai riwayat tidak sadar mulai dari awal cedera sampai di rumah sakit, tidak ada lucid interval, dan pupil yang anisokor. Jenis EDH yang terjadi pada pasien ini kemungkinan masih bersifat akut, namun operasi dilakukan setelah 24 jam sejak cedera/ benturan yang pertama terjadi disebabkan jauhnya perjalanan menuju rumah sakit, sehingga dapat diprediksi kemungkinan angka keberhasilan penanganan menjadi lebih kecil. Berdasarkan kronologisnya hematom epidural diklasifikasikan menjadi: 1). Akut: ditentukan diagnosisnya waktu 24 jam pertama setelah trauma; 2). Subakut: ditentukan diagnosisnya antara 24 jam -7 hari, 3). Kronis: ditentukan diagnosisnya hari ke $7 \cdot{ }^{10-13}$

\section{Pertimbangan Etika}

Pengambilan keputusan medik pada kasus ini tidak hanya memperhatikan aspek medik saja 
Tabel 1. Pertimbangan Etika Klinik ${ }^{8}$

\begin{tabular}{l}
\hline Indikasi medik \\
Beberapa pertanyaan terkait indikasi medik \\
1. Apakah yang menjadi masalah medis pasien ? \\
bagaimana riwayatnya? apa diagnosisnya dan \\
bagaimana prognosisnya ? \\
2. Apakah masalah tersebut akut, kronik, kritis, ga- \\
wat darurat, dan masih dapatkah disembuhkan? \\
3. Apakah tujuan akhir pengobatannya? \\
4. Berapa besar kemungkinan keberhasilannya? \\
5. Adakah rencana lain bila terapi gagal? \\
6. Sebagai tambahan, bagaimana pasien ini diun- \\
tungkan dengan perawatan medis, dan bagaima- \\
na kerugian dari pengobatan dapat dihindari ?
\end{tabular}

Permintaan pasien

Beberapa pertanyaan terkait permintaan pasien:

1. Apakah pasien secara mental mampu dan kompeten secara legal? apakah ada keadaan yang menimbulkan ketidakmampuan?

2. Bila berkompeten, apa yang pasien katakan mengenai pilihan pengobatannya?

3. Apakah pasien telah diinformasikan mengenai keuntungan dan risikonya, mengertiatau tidak terhadapinformasiyang diberikandanmemberikanpersetujuan?

4. Bila tidak berkompeten, siapa yang pantas menggantikannya? apakah orang yang berkompoten tersebut menggunakan standar yang sesuai dalam pengambilan keputusan?

5. Apakah pasien tersebut telah menunjukkan sesuatu yang lebih disukainya?

6. Apakah pasien tidak berkeinginan/tidak mampu untuk bekerja sama dengan pengobatan yang diberikan? kalau iya, kenapa?

7. Sebagai tambahan, apakah hak pasien untuk memilih untuk dihormati tanpa memandang etnis dan agama?

Kualitas hidup

1. Bagaimana prospek, dengan atau tanpa pengobatan untuk kembali ke kehidupan normal ?

2. Apakah gangguan fisik, mental, dan sosial yang pasien alami bila pengobatannya berhasil?

3. Apakah ada prasangka yang mungkin menimbulkan kecurigaan terhadap evaluasi pemberi pelayanan terhadap kualitas hidup pasien?

4. Bagaimana kondisi pasien sekarang atau masa depan, apakah kehidupan pasien selanjutnya dapat dinilai seperti yang diharapkan?

5. Apakah ada rencana alasan rasional untuk pengobatan selanjutnya?

6. Apakah ada rencana untuk kenyamanan dan perawatan paliatif?
Fitur kontekstual

Beberapa pertanyaan terkait fitur kontekstual:

1. Apakah ada masalah keluarga yang mungkin mempengaruhi pengambilan keputusan pengobatan?

2. Apakah ada masalah sumber data (klinisi dan perawat) yang mungkin mempengaruhi pengambilan keputusan pengobatan?

3. Apakah ada masalah faktor keuangan dan ekonomi?

4. Apakah ada faktor relegius dan budaya?

5. Apakah ada batasan kepercayaan ?

6. Apakah ada masalah alokasi sumber daya ?

7. Bagaimana hukum mempengaruhi pengambilan keputusan pengobatan?

8. Apakah penelitian klinik atau pembelajaran terlibat?

9. Apakah ada konflik kepentingan didalam bagian pengambilan keputusan didalam suatu institusi ? namun juga harus memperhatikan aspek etika klinik dan medikolegalnya. Kriteria pasien COT yang akan diberikan tindakan anestesi berdasarkan pertimbangan etika dapat dilakukan berdasarkan teori etika klinik dari Jonsen, Siegler dan Winslade. ${ }^{8}$ Menurut teori etika klinik dari Jonsen, Siegler dan Winslade, ada 4 kuadran yang dapat menjadi pertimbangan yaitu indikasi medik, permintaan pasien, kualitas hidup dan fitur kontekstual sehingga teori ini sering disebut four box method. Pengambilan keputusan untuk melakukan tindakan anestesi pada COT menurut teori etika klinik dari Jonsen, Siegler dan Winslade dapat dilihat pada tabel 1.

\section{Indikasi Medik}

Penentuan indikasi medik pada pasien COT dapat dilakukan dengan menggunakan prinsip beneficence dan nonmaleficence. Prinsip beneficence berarti terapi harus memberikan manfaat secara medis, sementara non-maleficence berarti jangan merugikan pasien baik secara 
medis maupun finansial. ${ }^{8}$ COT merupakan sebuah masalah besar di dunia kedokteran karena angka mortalitas dan morbiditas yang cukup tinggi. Secara umum COT sering disebabkan oleh kecelakaan lalu lintas seperti tabrakan kendaraan, tertabraknya pejalan kaki, dan terjatuh dari kendaraan. ${ }^{10}$

Pasien ini mengalami COT setelah terjatuh dari lantai 2 sebuah mesjid 15 menit sebelum masuk ke rumah sakit. Pada saat masuk rumah sakit pasien mengalami penurunan kesadaran, namun ibunya menyangkal pasien kejang dan muntah. Rencana di IGD akan dilakukan kraniotomi emergensi untuk evakuasi bekuan darah dengan diagnosis epidural dan subdural hematoma temporoparieto-occipital sinistra. Penanganan di IGD dilakukan pengelolaan dini terhadap hal-hal yang mengancam jiwa yaitu hipotensi dengan memberikan kristaloid, hipoksia dengan menjaga airway dan breathing, kemudian diputuskan apakah perlu dilakukan intubasi atau tidak. Masalah klinis pasien ini adalah kondisi pasien pada level ASA III-IV, pada pasien didapatkan airway clear, breathing dengan respiratory rate $35 \mathrm{kali} /$ menit, $\mathrm{SpO}_{2}$ 98\%, sirkulasi dengan tekanan darah 105/52 mmHg, nadi $111 \mathrm{kali} /$ menit, pupil anisokor $3 \mathrm{~mm} / 4 \mathrm{~mm}$, pasien mengalami peningkatan TIK akut, GCS menurun menjadi 6 (E2M2V2), nyeri kepala $(+)$, muntah $(+)$, kejang $(+)$. Pada pasien COT hampir selalu menjalani anestesi umum yang bertujuan untuk tindakan pembedahan, pemeriksaan penunjang radiologis, atau untuk memperbaiki ventilasi mekanik. Pada COT dapat mengakibatkan fraktur tulang kepala, memar otak, serta cedera pembuluh darah dan parenkim otak yang dapat menyebabkan perdarahan intrakranial dan peningkatan tekanan intrakranial (TIK). Proses ini berlanjut sampai terjadinya peradangan (inflamasi) serta edema otak yang akan memperparah peningkatan TIK dan pada akhirnya dapat menurunkan tekanan perfusi otak (TPO). ${ }^{11}$

Dengan diagnosis yang begitu berat, maka dapat diprediksi prognosis penyakit pasien. Prognosis pada pasien ini dubia et malem (mengarah ke buruk). Seperti telah dimaklumi bahwa efek COT secara umum dapat dikenali secara klinis yang terdiri dari 2 jenis, yaitu efek primer yaitu cedera kranioserebral langsung yang terjadi pada saat trauma dan efek sekunder yaitu cedera kranioserebral akibat komplikasi kerusakan primer misalnya edema serebri, kerusakan sawar darah otak, nekrosis jaringan, hipertermi, dan lainnya. ${ }^{10}$ Kondisi pasien ini akut dan tidak dapat sembuh seperti semula, tindakan akhir pengobatan melalui tindakan anestesi dan pembedahan hanya untuk dapat mempertahankan kebutuhan hidup dasar seperti memperbaiki kesadaran umum, membantu pernapasan adekuat, membantu jalan napas, menjaga sirkulasi agar dapat mempertahankan tekanan perfusi otak dan tekanan perfusi organ vital lainnya.

Tindakan medik diambil karena masih ada harapan sesuai indikasi. Tingkat keberhasilan pada kasus sebelumnya $40 \%$. Walaupun prognosis pasien ini kurang baik tetap diambil tindakan anestesi mengingat masih ada peluang untuk kesembuhan pasien. Ada rencana lain apabila tindakan gagal yaitu perawatan paliatif dan hal tersebut sudah dijelaskan kepada keluarga. Penanganan medik pada pasien ini memberikan manfaat buat pasien paling tidak untuk kelangsungan hidup berupa pengurangan tekanan intrakranial, serta memperbaiki tekanan perfusi otak, sementara kerugian tindakan operasi adalah stres operasi dan pengeluaran hormon kortison.

\section{Kualitas Hidup}

Sejak awal pasien dikonsulkan ke Bagian Anestesiologi Rumah Sakit Umum Daerah dr. Zainoel Abidin, dilakukan pemantauan secara menyeluruh termasuk pemeriksaan ada tidaknya jejas pada bagian tubuh yang lainnya. Hal tersebut penting mengingat pasien dengan cedera kepala biasanya mengalami cedera multipel. Riwayat mekanisme cedera berguna untuk menentukan kemungkinan potensi luasnya cedera kepala dan juga menunjukkan kemungkinan adanya cedera yang lain. Penilaian awal sebaiknya digunakan protokol yang disarankan oleh Advanced Trauma Life Support (ATLS) atau Primary Trauma Care (PTC). Cedera otak harus diperhatikan kemungkinan gangguan pada jalan napas dan sirkulasi; digunakan pendekatan "ABCDE" neuroanestesi untuk mengetahui cedera yang 
mengancam jiwa dan memerlukan penanganan segera. Pendekatan ABCDE neuroanestesi terdiri dari Airway, yaitu memastikan jalan napas aman, Breathing, dengan memberikan ventilasi dan oksigenasi adekuat, Circulation yaitu menstabilkan sistem kardiovaskular, Drug yaitu menghindari obat-obat dan tindakan anestesi yang meningkatkan tekanan intrakranial dan Environment yaitu mempertahankan suhu mild/ hipotermia. Setelah itu penanganan dirujuk ke divisi bedah saraf; selanjutnya bedah saraf akan mengamati nilai Glasgow Coma Score (GCS) saat pertama datang, dan GCS terbaru; juga ukuran dan reaksi pupil dan ada tidaknya tanda-tanda terkumpulnya darah dalam suatu sisi rongga kranium (tanda-tanda lateralisasi). ${ }^{11-14}$ Pasien ini mengalami cedera otak primer yang merupakan faktor utama penentu luaran keberhasilan terapi namun tidak boleh dikesampingkan bahwa pasien ini juga mengalami cedera otak sekunder yang akan lebih memperburuk luaran pasien. Kalau sudah terkena cedera otak sekunder maka prognosis pasien menjadi semakin memburuk. Pada pasien ini telah terjadi cedera otak sekunder berupa hipoksemia, hiperkarbia, hipovolemia, hipotermia, hipokalemia. Karena itu, anestesi untuk pasien cedera kepala harus melibatkan pencegahan cedera sekunder. ${ }^{11}$

Penyebab cedera sekunder bisa intrakranial bisa ekstrakranial atau sistemik. Penyebab intrakranial misalnya epidural, subdural, intraserebral hematoma, edema serebral, peningkatan TIK. Penyebab sistemik seperti hipoksemi, hiperkapni, hipotensi, anemi, hipertensi, hipoglikemi, hipertermi, sepsis. Penatalaksanaan cedera kepala difokuskan pada pencegahan dan pengelolaan cedera sekunder. ${ }^{12}$ Ada tiga sasaran Anesthesiologist selain memfasilitasi dapat dilakukan pembedahan yaitu (1) mengendalikan tekanan intrakranial dan volume otak, (2) melindungi jaringan saraf dari iskemia dan cedera, (3) mengurangi perdarahan. ${ }^{14}$ Keberhasilan penanganan cedera otak primer dan sekunder dapat mempengaruhi kualitas hidup paska tindakan anestesi dan pembedahan.

Pengukuran kualitas hidup ditentukan dengan menggunakan prinsip beneficence, non maleficence dan autonomy. Kualitas hidup merupakan suatu bentuk kepuasan, pernyataan nilai, pengalaman hidup dalam semua aspek menjadi lebih baik atau lebih buruk. ${ }^{11}$ Penentuan kualitas hidup pasien paska tindakan anestesi perlu dipertimbangkan karena kondisi pasien pra anestesi sudah buruk. Dokter ahli anestesi dan bedah syaraf telah memberikan informasi sejelas-jelasnya kepada keluarga pasien tentang prognosis dari penyakit yang diderita pasien, pada kasus ini pasien sudah dinyatakan ada kemungkinan meninggal di meja operasi, dilema etiknya adalah operasi tetap dilakukan atau tidak dilakukan dengan kemungkinan pasien akan meninggal dunia karena kondisi pasien sangat buruk. Pada kondisi ini maka pertimbangan etik dapat dilakukan dengan pendekatan prima facie dengan mengkedapankan kepentingan pasien yaitu tetap dilakukan operasi walau pada akhirnya pasien meninggal (paling tidak pasien masih punya peluang untuk tetap hidup) daripada tidak melakukan operasi (dengan kemungkinan pasien meninggal karena perburukan kondisi pasien), atau dapat juga dengan pendekatan minus mallum dengan memilih keburukan yang lebih minimal yaitu masih ada harapan hidup bila dilakukan operasi lebih memiliki risiko minimal dibandingkan dengan pasien meninggal tanpa dilakukan tindakan. Keluarga pasien sudah memahami informasi ini dan memberikan persetujuan dan menerima apapun yang akan terjadi pada pasien. ${ }^{8}$

\section{Permintaan Keluarga Pasien}

Permintaan pasien dan atau keluarganya dilayani dengan menggunakan prinsip Autonomy. Autonomy berarti setiap tindakan medis haruslah mendapat persetujuan dari pasien yang kompeten (atau keluarganya terdekat, dalam hal pasien tidak dapat memberikan persetujuannya). Pasien ini tidak memiliki kapasitas memberikan persetujuan karena masih berusia 5 tahun, pemberian persetujuan dilakukan oleh orangtuanya. Kepada orang tua pasien, dokter telah memberikan penjelasan terkait tindakan anestesi dan operasi yang akan dilakukan, alternatif tindakan, diagnosis dan prognosis. Secara khusus orang tua pasien tidak menyatakan permintaan namun hanya mengharapkan yang terbaik buat pasien. 
Dokter juga sudah menjelaskan dengan sejujurjujurnya tentang kondisi pasien, tidak ada benturan kepentingan dalam hal ini, keluarga pasien sangat kooperatif menyerahkan keputusan kepada tim dokter. Standar etik dan medikolegal untuk pengambilan keputusan yang diwakilkan didasarkan pada keputusan yang dibuat untuk pasien berdasarkan informasi tentang hak dan keinginan pasien yang sudah berjalan lama. Bagaimanapun nilai-nilai pasien dapat tidak diketahui, tidak ditemukan atau tidak dapat dilaksanakan. Pada kasus ini, perwakilan pengambilan keputusan harus berdasarkan standar panduan terbaik dalam identifikasi tatalaksana klinis yang melindungi dan mengutamakan kesehatan pasien. Dokter harus mengidentifikasi perwakilan pengambilan keputusan yang sesuai secara hukum. Disebutkan bahwa penandatangan persetujuan tindakan medik (informed consent) dapat dilakukan oleh orangtua, wali, keluarga terdekat atau induk semang. Persetujuan tindakan medik juga harus sesuai dengan kaidah-kaidah yang terdapat di dalam pasal 45 Undang-Undang Republik Indonesia Nomor 29 tahun 2004. ${ }^{15,16}$

\section{Fitur Kontekstual}

Fitur kontekstual didapatkan dengan menggunakan prinsip justice dan fairness. Walaupun etika klinik lebih fokus pada indikasi medis, permintaan pasien maupun kualitas hidup, namun keputusan medis tidak hanya diputuskan oleh dokter dan pasien tetapi juga harus mempertimbangkan aspek lain seperti sosial budaya, kepercayaan, agama, maupun finansial. ${ }^{8}$ Biasanya Fitur kontekstual yang mempengaruhi keputusan etik adalah finansial, agama dan budaya. Pada pasien ini tidak ada konflik kepentingan dalam pengambilan keputusan. Tidak ada masalah keluarga yang mempengaruhi pengambilan keputusan pengobatan, masalah finansial pun tidak ada karena pasien ditanggung oleh Badan Penyelenggara Jaminan Sosial (BPJS) Kesehatan, juga tidak ada hambatan faktor relegius dan budaya. Aspek etika dalam situasi klinik sering menimbulkan dilema etik berupa dilema antara indikasi medik vs preferensi pasien, indikasi medik vs kualitas hidup dan indikasi medik vs gambaran kontekstual. ${ }^{8}$ Indikasi medik pada pasien ini adalah kondisi pasien pada level
ASA III-IV. Diagnosis pasien ini adalah COT berat dengan epidural dan subdural hematoma temporoparieto-occipital sinistra. Tindakan yang akan dilakukan kraniotomi evakuasi. Walau harapan sembuh sangat kecil, namun dokter harus tetap melakukan yang terbaik buat pasien. Alternatif tindakan yang dapat ditawarkan pada pasien dengan kondisi terminal adalah perawatan paliatif. ${ }^{17}$

Perawatan paliatif harus disesuaikan dengan stadium dan prognosis penyakit pasien, karena pemberian perawatan yang tidak sesuai, baik itu lebih maupun kurang, hanya akan menambah penderitaan pasien. Pemberian perawatan yang berlebihan beresiko untuk memberikan harapan palsu kepada pasien yang bisa saja perawatan itu menjadi sia-sia. Hal ini berhubungan dengan masalah etika klinik. Perawatan yang diberikan hanya karena dokter merasa harus melakukan sesuatu meskipun itu sia-sia adalah tidak etis. ${ }^{17}$

\section{Simpulan}

Dalam konteks dilema etik yang muncul seperti kasus di atas, dokter harus mampu berkomunikasi dengan baik, jujur dan terbuka dalam menyampaikan informasi terkait diagnosa dan prognostik kepada keluarga pasien. Jika dokter tidak nyaman memberikan informasi tersebut, maka dapat dibantu oleh seorang tenaga profesional yang berkualifikasi memadai dalam hal komunikasi yang efektif. Pada saat yang sama, dokter juga harus peka terhadap kebutuhan emosional dan psikologis keluarga. Pengambilan keputusan medik yang dibarengi dengan keputusan etik sangat dianjurkan. Pada pasien ini telah dilakukan pertimbangan etik yang menghasilkan keputusan bersama antara tim dokter dengan keluarga pasien. Walau pada akhirnya pasien ini tidak berhasil diselamatkan, paling tidak keluarga pasien puas atas pelayanan rumah sakit karena informasi mengenai indikasi medik tindakan terhadap pasien disampaikan sejelas-jelasnya dengan tetap memperhatikan sudut pandang permintaan (keinginan) pasien, kualitas hidup maupun fitur kontekstual yang menyertainya. 


\section{Daftar Pustaka}

1. Awaloei AC, Mallo NTS, Tomuka D. Gambaran cedera kepala yang menyebabkan kematian di Bagian Forensik dan Medikolegal RSUP Prof. Dr. R. D. Kandou. J e-Clinic. 2016;4:2-6.

2. Aghakhani K, Heidari M, Yousefinejad V, Okazi A. Frequency of intracranial injury in cadavers with head trauma with and without scalp injury in Teheran. J Forensic Leg Med. 2014;28:36-38.

3. Imran. Karakteristik dan outcome pasienpasien penyakit neurologis. Kedokteran Unversitas Syiah Kuala. 2017;17:168-73.

4. Stankov A, Cakar L, Bitoljanu N, Belakaposka- Srpanova V, Bujaroska $\mathrm{M}$ and CZ. Forensik a spect of cerebral contusions. Maced Med Rev. 2014:101-03.

5. Li M, Zhao Z, Yu G, Zhang J. Epidemiology of traumatic brain injury over the world: a systematic review. Gen Med Open Access. 2016;04(05):1-14.

6. Badan Penelitian dan Pengembangan Kesehatan Kementerian Kesehatan RI Riset Kesehatan Dasar. Dep Kesehat RI. 2013;(1):1-303.

7. Honeybul S, Gillett IG, Ho K, Lind C. Ethical considerations for performing decompressive craniectomy as a life-saving intervention for severe traumatic brain injury. J Med Ethics. 2012;38:657-661.

8. Jonsen AR, Siegler M, Winslade WJ. Clinical ethics: a practical approach to ethicaldecisions in clinical medicine. 7th ed. Philadelphia, USA: McGraw-Hill Medical Publishing Division, 2010: 9-225.
9. Mayo CD, Lara VS, Robinson K, Gawryluk JR. Neuropsychological assessment of traumatic brain injury: Current ethical challenges and recommendations for future practice. Applied Neuropsychology. 2019; 26 (4): 383-91.

10. Lalenoh DC, Sudjito NH, Suryono B. Penanganan anestesi pada cedera otak traumatik. Jurnal Neuroanestesi Indonesia. 2012;1(2):120-32.

11. Syah BIA, Suarjaya IPP, Rahardjo S, Saleh SC. Penatalaksanaan anestesi pada pasien cedera kepala berat akibat hematoma epidural akut disertai kehamilan. Jurnal Neuroanestesi Indonesia. 2017;6 (3): 169-77.

12. Basuki WS, Suryono B, Saleh SC. Penatalaksanaan perioperatif cedera kepala traumatik berat dengan tanda cushing. Jurnal Neuroanestesi Indonesia. 2015;4 (1): 34-42.

13. Martiniuc C, Dorobat GH. Polytrauma with severe traumatic brain injury. Case report. Romanian Neurosurgery, 2010; XVII (1): $108-13$.

14. Bisri T. Penanganan Neuroanestesia dan Critical Care Cedera Otak Traumatik. Bandung. Fakultas Kedokteran Universitas Padjadjaran. 2012:83-124.

15. Dahlan S. Informed consent, dalam hukum kesehatan-rambu-rambu bagi profesi dokter, edisi 3, Badan Penerbit Universitas Diponegoro Semarang. 2005:39-50.

16. Republik Indonesia. Undang-Undang Nomor 29 Tahun 2004 Tentang Praktik Kedokteran. Jakarta; 2004.

17. Rasjidi I. Perawatan Paliatif Suportif dan Bebas Nyeri pada Kanker. Jakarta. CV Sagung Seto. 2010: 1-42. 